\title{
VULNERABILIDADE NATURAL DAS ÁGUAS SUBTERRÂNEAS EM ÁREA DO TABULEIRO DO MARTINS - MACEIÓ - ALAGOAS - BR
}

\author{
José Vicente Ferreira Neto \\ Rua Mariontina Cavalcante, 16, Pajuçara - 57030-610 - Maceió - AL \\ Telefone/Fax: (82) 231-1430; E-mail: ferreira@fapeal.br
}

\author{
Ricardo José Queiroz dos Santos \\ Conjunto Carajás, Rua E, 42, Serraria - 57046-390 - Maceió - AL \\ Telefone: (82) 328-2028; E-mail: rcalima@fapeal.br \\ Paulo Roberto Bezerra Wanderley \\ Rua Rivadávia Carnaúba, 23, Farol - 57057-260 - Maceió - AL \\ Telefone: (82) 241-9457; E-mail: paulow@rural.com.br

\section{Perillo Rostan de Mendonça Wanderley} \\ Rua Rivadávia Carnaúba, 23, Farol - 57057-260 - Maceió - AL \\ Telefone: (82) 241-9457; E-mail: prmw@fapeal.br
}

\section{Abel Tenório Cavalcante}

Av. Álvaro Otacílio, 6889, Ap. 603, Jatiúca - 57037-270 - Maceió - AL Telefone/Fax: (82) 355-2122; E-mail: ablltc@dialnet.com.br

Tema: Uso e Proteção de Águas Subterrâneas

RESUMO: Foi estudada uma área localizada no domínio dos Tabuleiros Costeiros de Maceió, dentro da Bacia Sedimentar de Alagoas, onde as águas subterrâneas são intensivamente explotadas para consumo humano e industrial. Possui clima tropical, subúmido seco, com baixa amplitude térmica e precipitações anuais em torno de $1480 \mathrm{~mm}$. Trata-se de uma bacia evaporimétrica, onde a recarga dos sistemas aqüíferos se dá principalmente pela infiltração do excedente de águas pluviais, estimada em $400 \mathrm{~mm}$ anuais. Das unidades litoestratigráficas, somente as formações Barreiras, Marituba e Poção são explotadas isoladamente ou em conjunto, quando formam um só sistema aqüífero. Dentre as atividades potencialmente poluidoras identificadas, destacam-se: sistemas de esgotamento sanitário, efluentes líquidos industriais, postos de combustíveis, e o sistema de drenagem da região, constituído de lagoas para amortecimento de cheias 
que são também utilizadas como corpos receptores de efluentes domiciliares e industriais. Apesar das atividades potencialmente poluidoras, o risco de contaminação é atenuado devido à baixa vulnerabilidade em cerca de $80 \%$ da área. É mais provável a contaminação dos sistemas aqüíferos nas áreas de vulnerabilidade moderada.

\section{INTRODUÇÃO}

Sendo a água um recurso natural renovável e um bem que deve ser utilizado pelo homem para sua sobrevivência e melhoria de suas condições econômicas e sociais, torna-se evidente a necessidade de mantê-la com a qualidade e em quantidade suficientes ao atendimento dos seus diversos usos. Contudo, devido ao incremento de sua utilização, resultante do crescimento populacional e do desenvolvimento industrial e agrícola, este recurso natural pode se tornar poluído ou mesmo escasso.

Em Maceió, segundo a concessionária de abastecimento d'água, os recursos hídricos subterrâneos representam mais de $80 \%$ do consumo total e grande parte dos poços de captação se localizam na região do Tabuleiro do Martins. Maior preocupação, portanto, deve-se ter, localmente, em preservar a qualidade dessas águas subterrâneas visto que, uma vez contaminadas, a sua recuperação certamente exigirá pesados investimentos além do longo período de tempo demandado.

Esse trabalho tem por objetivo mostrar a situação atual do uso do solo e 58 das águas de uma área localizada no bairro do Tabuleiro do Martins, em Maceió / AL, onde o elevado nível de explotação das águas subterrâneas compromete sua qualidade e quantidade, além de apresentar o grau de vulnerabilidade dessas águas.

A área estudada está situada no domínio dos Tabuleiros Costeiros do Estado de Alagoas, na região norte da cidade de Maceió, num interflúvio tabuliforme pouco dissecado delimitado pelos rios Carrapatinho/Catolé, Messias ou do Meio, Riacho Doce, Jacarecica e Reginaldo, totalizando cerca de $42,8 \mathrm{Km}^{2}$, definida pelos paralelos $9^{\circ} 31^{\prime} 31^{\prime \prime}$ e $9^{\circ} 35^{\prime} 00^{\prime \prime}$ de Latitude Sul e pelos meridianos $35^{\circ} 44^{\prime} 18^{\prime \prime}$ e $35^{\circ} 47^{\prime} 56^{\prime \prime}$ de Longitude Oeste de Greenwich, (Figura 01).

\section{CARACTERÍSTICAS FÍSICAS DA} ÁREA

\section{1 - Clima}

De acordo com a classificação climática de THORNTHWAITE-MATHER (1955), Maceió possui clima sub-úmido seco, com deficiência d'água moderada, megatérmico, com evapotranspiração potencial anual média de $1193 \mathrm{~mm}$ e 
concentração da evapotranspiração Os ventos são de sudeste e nordeste, potencial no quadrimestre outubro-janeiro, sendo que os de nordeste são quase correspondente aos meses mais quentes sempre de verão. O vento predominante é do verão, igual a 39\%. Caracteriza um de sudeste.

clima tropical, com baixa amplitude térmica.

A média mensal de insolação varia de A umidade relativa do ar atinge o máximo de $82,9 \%$ no mês de maio e a mínima de $75,7 \%$ no mês de novembro.

5,7 a 6,2 h/dia na estação chuvosa, meses de maio a julho, atingindo o máximo médio de 9,3 h/dia no verão (novembro a janeiro).

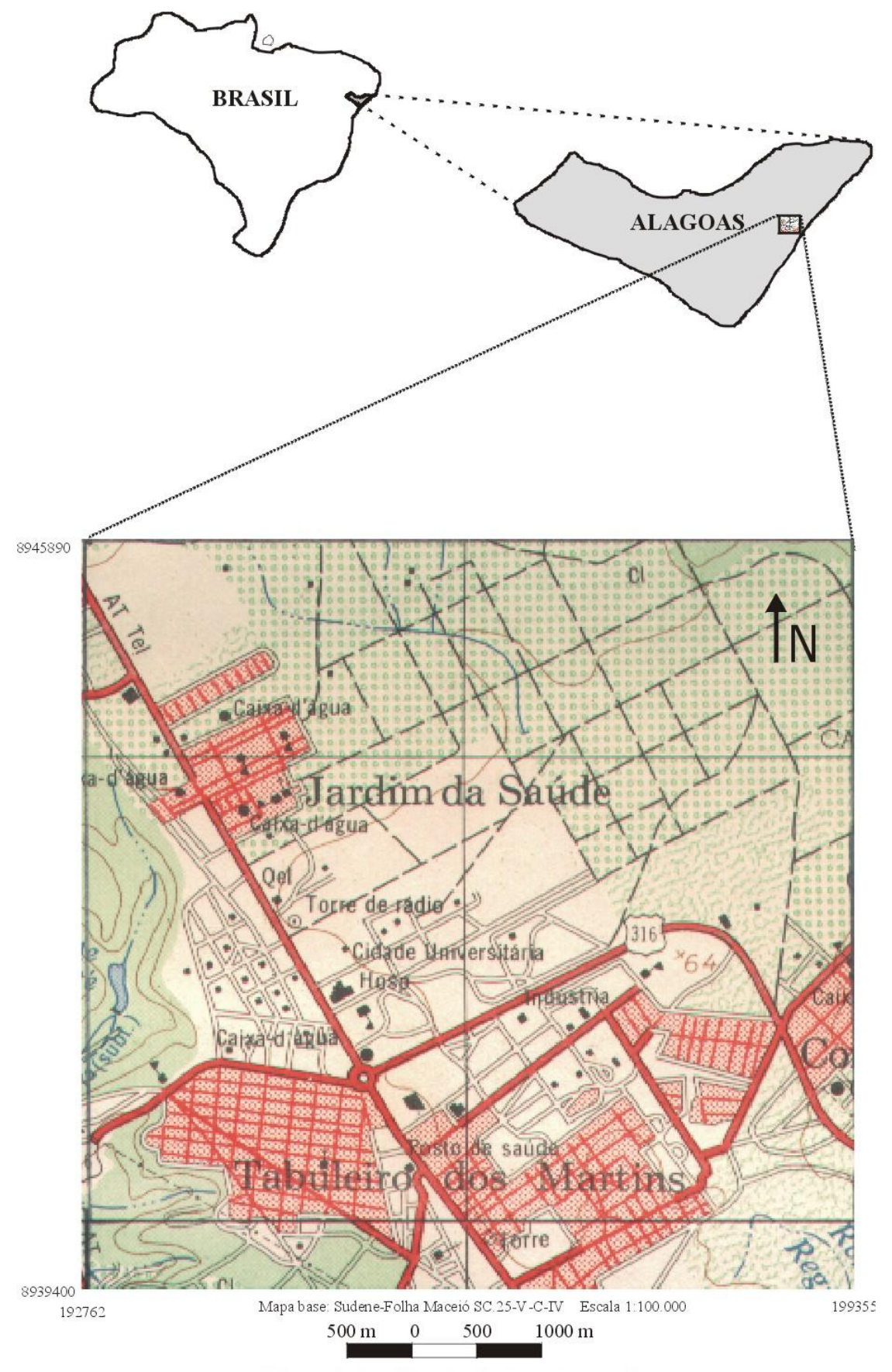

Figura 01 - Mapa de localização da área de estudo 
A região está associada a chuvas. Caracteriza-se também por temperaturas elevadas o ano todo, com apresentar baixos índices de nebulosidade. amplitudes térmicas máximas de $6^{\circ} \mathrm{C}$ A pluviometria anual referente à Entretanto, a relativa homogeneidade Estação Maceió, série de 1913 a 1985 térmica contrasta-se com a grande (SUDENE, 1990), representada na Figura variabilidade espacial e temporal das 02, apresenta uma média de 1478,6 mm.

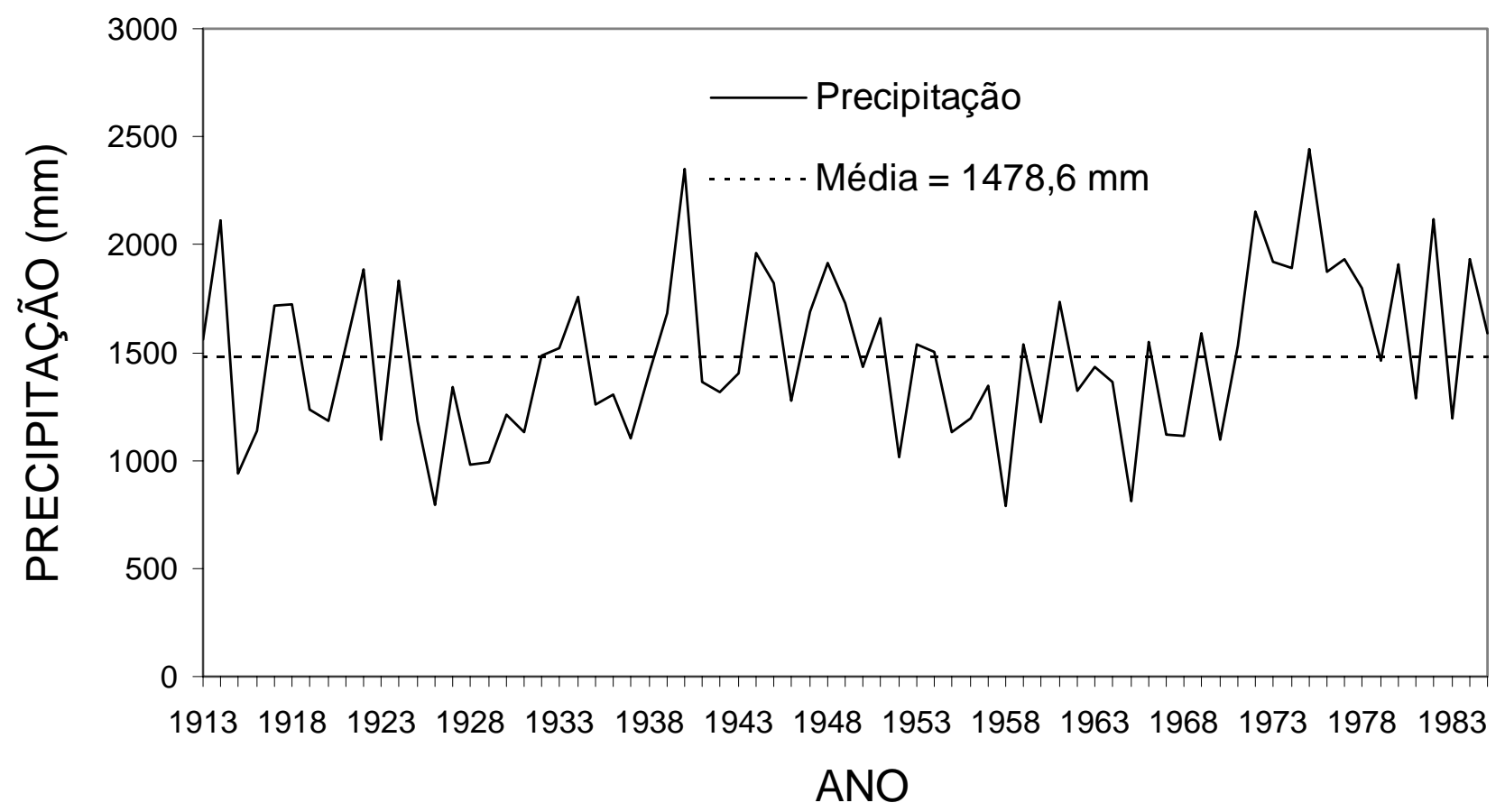

Figura 02 - Pluviometria anual, Estação Maceió (1913 a 1985) Fonte: SUDENE

O balanço hídrico cíclico (Figura 03), Apresenta as seguintes foi obtido pelo método de características:

THORNTHWAITE-MATHER pluviometria (SUDENE), e as médias mensais de temperatura e evaporação (INMET), para o cálculo da evapotranspiração potencial, corrigindo-se os valores obtidos para a duração real do mês e para o número máximo de horas de sol, (TUCCl, 1993).
- O mês de março é, potencialmente, o período de reposição hídrica.

- O período de abril a agosto corresponde ao período de excedentes hídricos.

- O período de setembro a dezembro corresponde ao período tanto de retirada d'água do solo como também de deficiência hídrica. 
- O período de janeiro a fevereiro corresponde exclusivamente ao período de deficiência hídrica.

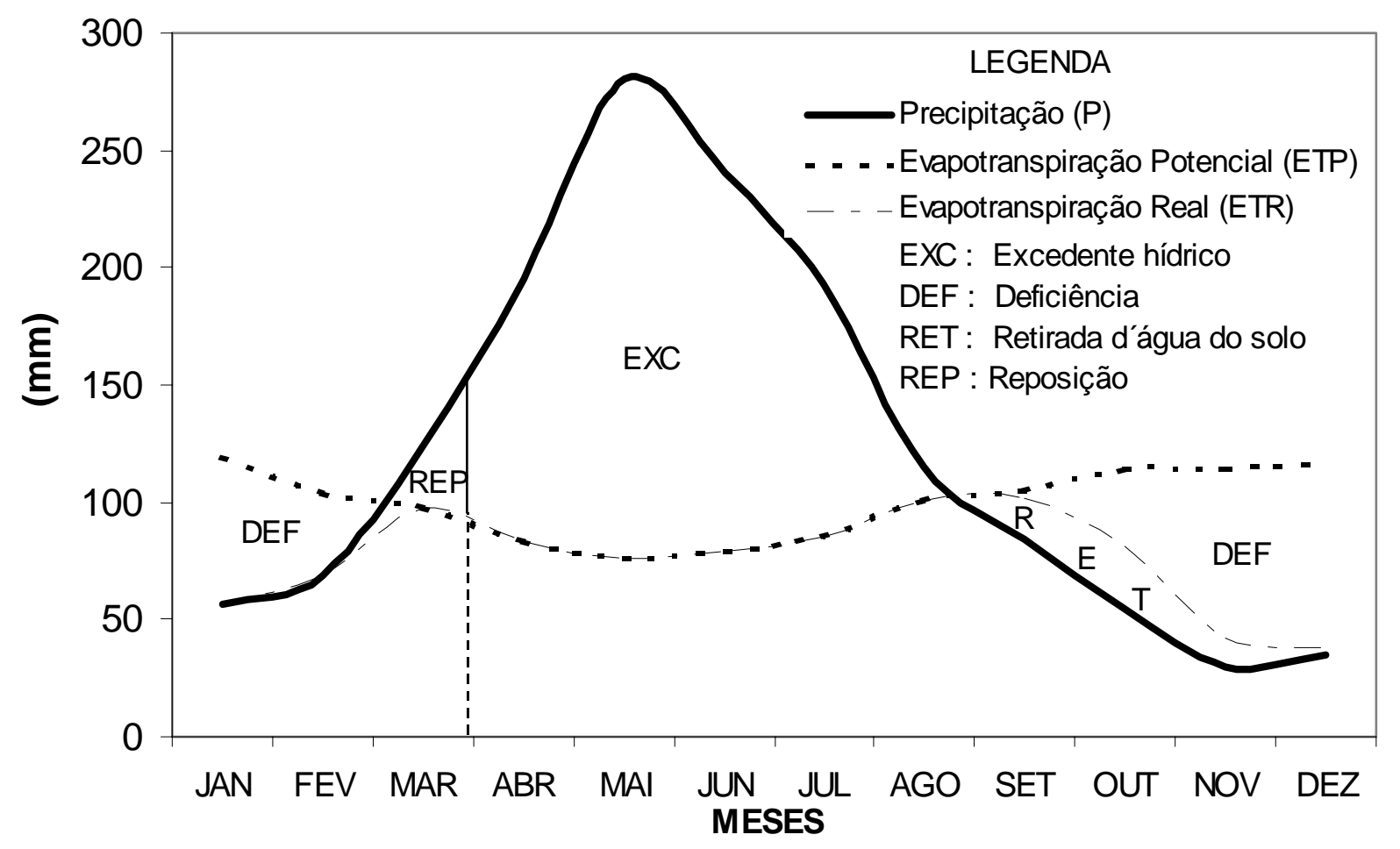

Figura 03 - Balanço hídrico de Maceió segundo Thornthwaite-Mather

Por se tratar de uma bacia endorreica para diferentes períodos de retorno ou ou evaporimétrica, a recarga anual de água diferentes probabilidades de ocorrência da subterrânea na região pode ser estimada mesma, conforme apresentado na Tabela através do cálculo do excedente hídrico, 01, através da distribuição de probabilidade obtido pelo balanço mensal contabilizado do tipo Log-normal, que apresentou melhor para os anos com disponibilidade de dados ajuste aos totais anuais obtidos, (Figura de evaporação (Estação INMET, período: 04).

1946 a 1969).

Com base nos totais anuais de excedente hídrico estimou-se a recarga 


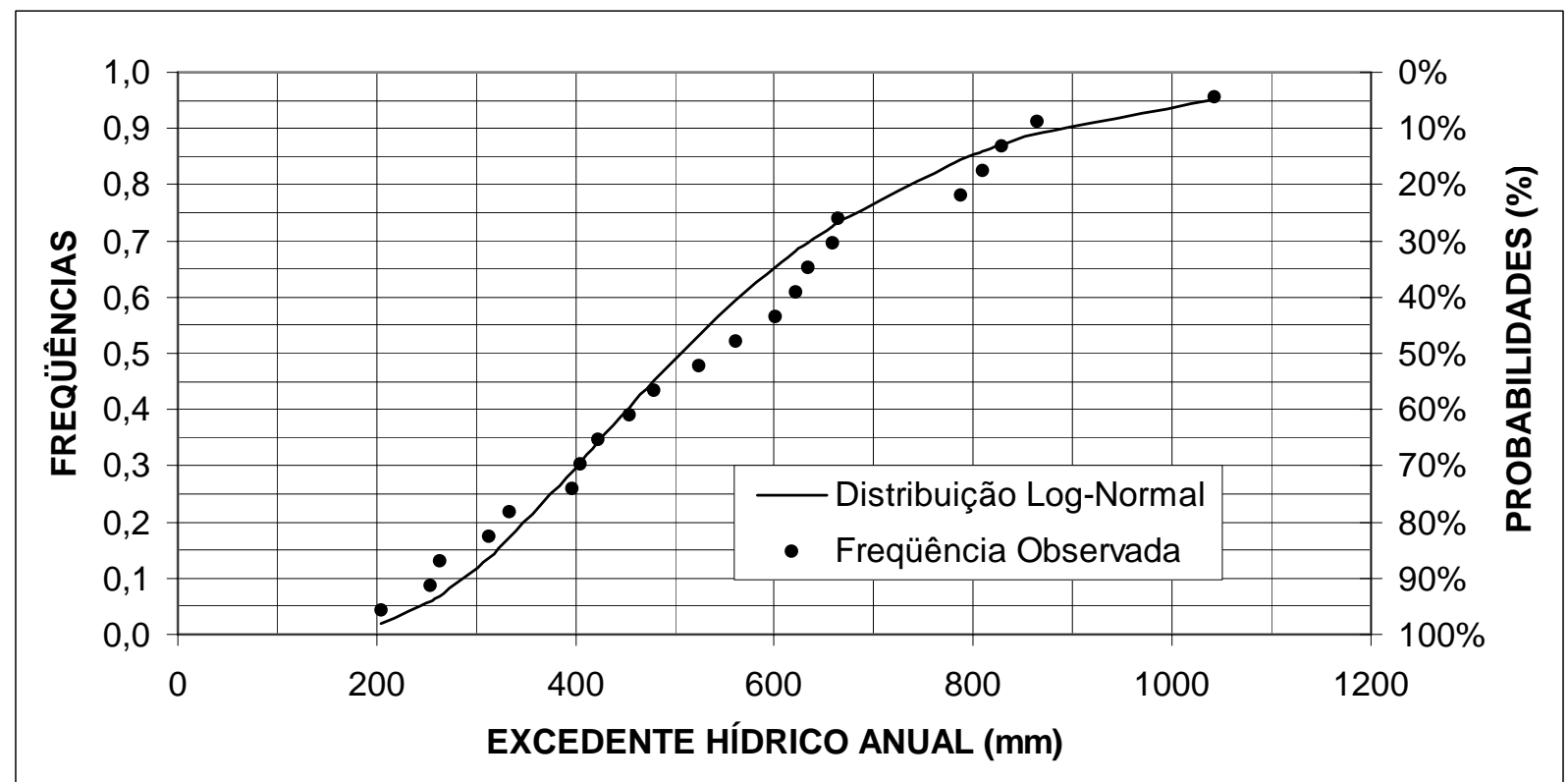

Figura 04 - Distribuição de freqüências do excedente hídrico anual

Tabela 01 - Estimativa do excedente hídrico anual

\begin{tabular}{|l|c|c|c|c|c|c|}
\hline Período de retorno (anos) & 2 & 5 & 10 & 20 & 50 & 100 \\
\hline Probabilidade (\%) & 50 & 80 & 90 & 95 & 98 & 99 \\
\hline Excedente hídrico (mm/ano) & 505,5 & 349,6 & 288,4 & 245,9 & 205,6 & 182,4 \\
\hline
\end{tabular}

\section{2 - Geomorfologia}

A morfologia predominante na região é a dos tabuleiros costeiros elaborados desde o Terciário Superior a partir dos depósitos da Formação Barreiras. Essa superfície é designada de "Superfície dos Tabuleiros" (MABESSONE \& CASTRO, 1975). Apresenta declividade média de 3 metros por quilômetro no sentido leste e termina próximo à costa sob a forma de falésias que bordejam a planície costeira.

Excetuando-se as áreas localizadas na porção superior das bacias dos rios Reginaldo e Jacarecica, o relevo da área mostra uma conformação de bacia endorreica, com as menores cotas (em torno de $65 \mathrm{~m}$ ) formando uma depressão ou lagoa, localizada na área de interesse. Essa configuração é de grande importância para os aqüíferos subjacentes, fazendo da área preferencialmente uma zona de recarga, por favorecer sobremaneira a infiltração direta a partir das precipitações.

A cota máxima observada na área é de $112 \mathrm{~m}$, na parte sudoeste da mesma, contrastando com a falésia que logo se inicia em direção ao vale do rio Mundaú.

\section{3 - Hidrologia superficial}


A sudeste, no limite da área estudada, localiza-se a porção superior da bacia do rio Reginaldo, caracterizado como um rio influente. O leito do alto e médio Reginaldo só apresenta vazões na ocorrência de precipitações que supram a deficiência de umidade do solo ou que excedam sua capacidade de infiltração, cessando logo após terminada a chuva. O baixo Reginaldo se apresenta perene principalmente devido ao despejo contínuo em seu leito das águas servidas pela população ribeirinha.

A leste da área também está localizada a porção superior da bacia hidrográfica do rio Jacarecica, caracterizado como efluente, apresentando-se perene em quase toda sua extensão, em função da contribuição da água do lençol subterrâneo ao curso d’água.
O restante da área estudada faz parte do Tabuleiro do Martins, onde toda a água superficial provém das chuvas e escoa, geralmente, para as depressões naturais existentes na área ou para as lagoas de acumulação escavadas com a finalidade de atenuar as cheias, muito comuns na região, de onde evapora ou infiltra no solo, contribuindo para a recarga do aqüífero.

CAVALCANTE et al. (1992), estudando as reservas dinâmicas de aqüíferos da região, através de análise de hidrógrafas, estimou para algumas pequenas bacias próximas à área de estudo, os coeficientes de esgotamento e volumes infiltrados ou descargas, que correspondem a contribuição de base, conforme Tabela 02.

Tabela 02 - Coeficientes de esgotamento e volumes infiltrados

\begin{tabular}{|l|c|c|c|c|}
\hline Bacias & $\begin{array}{c}\text { Áreas } \\
\left(\mathbf{k m}^{\mathbf{2}} \mathbf{)}\right.\end{array}$ & $\begin{array}{c}\text { Coeficiente } \\
\mathbf{d e} \\
\text { esgotamento }\end{array}$ & $\begin{array}{c}\text { Infiltração } \\
\left(\mathbf{1 0 ^ { 6 }} \mathbf{m}^{\mathbf{3}} \text { /ano) }\right.\end{array}$ & $\begin{array}{c}\text { Lâmina } \\
\text { infiltrada } \\
\text { (mm/ano) }\end{array}$ \\
\hline Remédios & 42 & 0,006 & 21,0 & 500 \\
\hline Messias & 70 & 0,006 & 20,0 & 286 \\
\hline Pratagy & 53 & 0,007 & 17,0 & 321 \\
\hline \multicolumn{5}{r}{} \\
\hline
\end{tabular}

Observa-se que a bacia do rio distribuição log-normal para um período de Messias, localizada no limite superior da retorno de 10 anos, portanto, com uma área, apresenta uma lâmina infiltrada de probabilidade de ocorrência de 90\%, 286 mm/ano, valor correspondente ao (Tabela 01).

excedente hídrico anual determinado pela 


\section{GEOLOGIA}

A Bacia Sedimentar Sergipe-Alagoas, onde está inserida a área de estudo, foi individualizada por FEIJÓ (1994), em função das importantes diferenças estruturais e estratigráficas, nas bacias Sergipe e Alagoas.

A Bacia Alagoas ocupa uma faixa alongada costeira de cerca de $220 \mathrm{~km}$ de extensão e $40 \mathrm{~km}$ de largura média, tendo como limite norte, o Alto de Maragogi da Bacia Pernambuco-Paraíba e ao sul, o Alto de Japoatã-Penedo da Bacia Sergipe.

As perfurações realizadas pela PETROBRÁS S.A. na região, penetraram as seguintes unidades litoestratigráficas: Formação Barreiras; Grupo Piaçabuçu (Formações: Marituba, Mosqueiro e Calumbi); Grupo Sergipe (Formações: Cotinguiba e Riachuelo); Grupo Coruripe (Formações: Maceió, Poção, Ponta Verde e Coqueiro Seco); Grupo Perucaba (Formações: Serraria, Bananeiras e Candeeiro); Grupo Igreja Nova (Formações: Acararé e Batinga).

\section{4 - CARACTERÍSTICAS}

\section{HIDROGEOLÓGICAS}

Atualmente, das unidades mencionadas, são conhecidas regionalmente como aqüíferos: Formação Barreiras; Formação Marituba do Grupo Piaçabuçu; e Formação Poção do Grupo Coruripe.
Segundo estudos de CAVALCANTE et al. (1982), os aqüíferos, na região, apresentam-se sob duas formas distintas. Numa faixa que se inicia ao norte de Maceió nas margens da lagoa Mundaú e se estende para nordeste, a Formação Barreiras está sobreposta aos sedimentos do Grupo Piaçabuçu representado principalmente pela Formação Marituba, ora funcionando como um só sistema aqüífero, ora como sistemas isolados, quando separados por camadas mais argilosas. E, no restante da região, a Formação Barreiras passa em profundidade para outras unidades mais antigas do que a Formação Marituba, podendo também formar um só sistema ou aqüíferos isolados.

Os perfis dos poços da área mostram a ocorrência dos sistemas Barreiras, Barreiras/Marituba e Barreiras/Poção, que ora se apresentam livres, ora confinados.

A maioria dos poços da região explotam água da Formação Barreiras e, somente em alguns, foram aproveitadas as seções arenosas da Formação Marituba e da Formação Poção para posicionamento de seções filtrantes.

A Formação Barreiras, de idade Neocenozóica, é composta por areais quartzosas com intercalações de argilas e siltes de cores variegadas e com bolsões ou mesmo camadas de seixos rolados em diversos níveis apresentando, 
ocasionalmente, blocos de canga fanglomerado em matriz de arcósio, arcósio ferruginosa. Variações lateral e vertical de conglomerático e arcósio, via de regra, fácies ocorrem muito irregularmente, sendo constante, na maioria dos perfis, um horizonte basal constituído por arenito conglomerático ou mesmo conglomerado.

A partir de testes em poços que penetram o aqüífero Barreiras, utilizando o método de JACOB (1964), foram estimados os parâmetros hidráulicos: coeficiente de transmissividade (T) e condutividade hidráulica (K) para este sistema aqüífero. Os resultados obtidos variaram, conforme:

- Transmissividade $1,6 \times$ $10^{-4}$ a $2,4 \times 10^{-2} \mathrm{~m}^{2} / \mathrm{s}$

- Condutividade hidráulica: ..... 9,4 x $10^{-6}$ a $8,9 \times 10^{-4} \mathrm{~m} / \mathrm{s}$.

A Formação Marituba que era, segundo SCHALLER (1969), um membro da Formação Piaçabuçu, é predominantemente composta por arenito médio a grosso de cor cinza. Esta unidade foi depositada entre o Campaniano e o Holoceno (FEIJÓ, 1994).

As areias grossas da Formação Marituba foram parcialmente penetradas em alguns poços da área estudada, apresentando, em cinco poços que captaram exclusivamente esta formação, um intervalo de transmissividade de 2,55 a $8,99 \times 10^{-4} \mathrm{~m}^{2} / \mathrm{s}$.

A Formação Poção, que ocorre como subafloramento discordante com a Formação Barreiras, é constituída por um biotítico. Os seixos e matacões são de rochas intrusivas ácidas e gnaisses, leitos de folhelhos cinza-esverdeados ocorrem intercalados.

Em dois poços localizados mais a NW foram penetrados os arcósios conglomeráticos da Formação Poção.

Para o sistema Barreiras/Marituba, utilizando dados de poços parcialmente penetrantes, os valores encontrados foram:

- Transmissividade $1,99 \times$ $10^{-4}$ a $6,62 \times 10^{-3} \mathrm{~m}^{2} / \mathrm{s}$

- Condutividade hidráulica: $4,5 \times$ $10^{-6}$ a $2,4 \times 10^{-4} \mathrm{~m} / \mathrm{s}$.

Não foram estimados os parâmetros hidráulicos do sistema aqüífero Barreiras/Poção, tendo em vista a não disponibilidade de dados de teste de aqüífero, no entanto, CAVALCANTE (1978), cita valores de transmissividade que variaram de 0,513 a 2,334 x $10^{-4} \mathrm{~m}^{2} / \mathrm{s}$ para a região de Santa Luzia, nas proximidades da área.

Os valores dos parâmetros hidráulicos mostrados acima indicam que o sistema aqüífero Barreiras é, localmente, de média a alta potencialidade, e o sistema Barreiras/Marituba de média potencialidade.

A recarga processa-se, principalmente, através da infiltração direta a partir das precipitações, seja na própria 
área estudada ou na região a montante do escoamento subterrâneo. A morfologia predominante de tabuleiros, com drenagem pouco desenvolvida a incipiente, facilita a recarga direta.

Conforme balanço hídrico apresentado no item 2.1, estima-se que $70 \%$ do excedente hídrico da região infiltra diretamente no solo, recarregando o aquífero. Este valor corresponde a cerca de $27 \%$ da precipitação média anual, ou seja: uma taxa de infiltração média de 400 mm anuais.

\section{USO DOS SOLOS E DAS ÁGUAS SUBTERÂNEAS}

A área do Tabuleiro do Martins apresenta:

- topografia plana com altitude média de 80 metros;

- facilidades para captação de água subterrânea de boa potabilidade através de poços tubulares com profundidade média de 100 metros; e

- solos com boas características para fundações.

Assim, por causa destas vantagens, houve grande expansão urbana com implantação de conjuntos habitacionais, indústrias e outras atividades sócioeconômicas.

Para conhecer o potencial de risco de contaminação das águas subterrâneas, foi inicialmente elaborado o mapa de uso do 66 solo apresentado na Figura 05. Em função da diversidade de ocupação, apresentada neste mapa e identificadas no campo, foram analisadas as atividades potencialmente poluidoras:

-Abastecimento d'água.

- Atividades agrícolas;

- Atividades industriais;

- Postos de combustíveis;

- Resíduos sólidos;

- Sistema de drenagem; e

- Sistema de saneamento.

\section{1 - Abastecimento d'água}

A alternativa mais econômica para o abastecimento da região é água subterrânea, por apresentar baixos custos de explotação e não necessitar de tratamento. Atualmente, mais de $80 \%$ da água consumida na Grande Maceió, para os diversos fins, é de origem subterrânea.

$\mathrm{Na}$ Tabela 03 encontra-se a estimativa de explotação de água subterrânea para o atendimento do consumo urbano e industrial da região. Para os poços da bateria da CASAL e os condominiais, foi considerado um regime de 24 horas/dia e para os poços isolados, 8 horas/dia. 
Tabela 03 - Explotação de água subterrânea

\begin{tabular}{|c|c|c|}
\hline POÇOS & QUANTIDADE & VAZÃO ( $\left.\mathrm{m}^{3} / \mathrm{dia}\right)$ \\
\hline - Baterias da CASAL & 39 & 44.060 \\
\hline - Baterias condominiais & 16 & 7.220 \\
\hline - Demais poços & 34 & 3.810 \\
\hline Totais: & 89 & 55.090 \\
\hline
\end{tabular}

Alguns poços são construídos sem as poços abandonados que não foram mínimas condições técnicas tamponados com cimentação.

recomendadas. É comum a ocorrência de

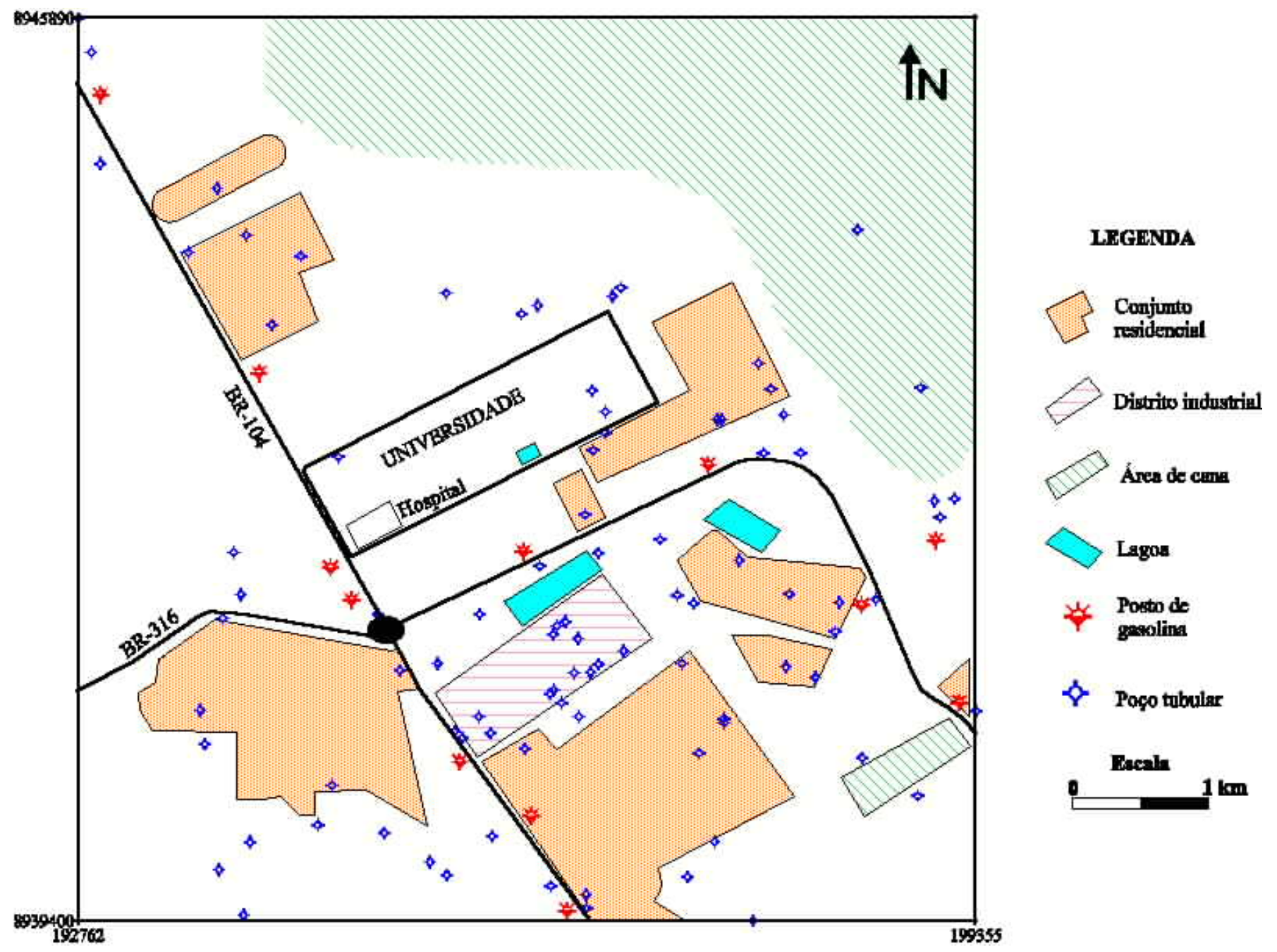

Figura 05 - Mapa de uso do solo 


\section{2 - Atividades Agrícolas}

Nas proximidades ao norte, se desenvolve a cultura da cana-de-açúcar, principal atividade agrícola, com intensivo uso de fertilizantes e pesticidas e irrigação com solução aquosa de vinhoto. Os excedentes do vinhoto são acumulados em lagoas, para infiltração através de sulcos no terreno.

Essas lagoas recebem um grande volume de vinhaça na época da safra.

\section{3 - Atividades Industriais}

As empresas do Distrito Industrial Governador Luiz Cavalcante, são de pequeno e médio porte. No Quadro 01 estão discriminadas as indústrias que apresentam efluentes líquidos, seus produtos, tipos de efluentes, além dos diversos tratamentos e disposição final destes efluentes.

As outras empresas localizadas fora desse Distrito Industrial, quando têm efluentes líquidos, geralmente destinam os mesmos, sem tratamento, para sumidouros semelhantes aos dos sistemas de esgotamento sanitário, acima descritos.

\section{4 - Postos de Combustíveis}

Foram localizados diversos postos de combustíveis, conforme Tabela 04.

Tabela 04 - Relação dos Postos de Combustíve
\begin{tabular}{|c|c|}
\hline TEMPO DE OPERAÇÃo & QUANTIDADE \\
\hline Menos de 10 anos & 06 \\
\hline De 10 a 30 anos & 03 \\
\hline Mais de 30 anos & 04 \\
\hline TOTAL: & $\mathbf{1 3}$ \\
\hline
\end{tabular}

Os postos com mais de 30 anos de operação necessitam de uma detalhada vistoria para se conhecer suas condições de estanqueidade.

\section{5 - Resíduos sólidos domésticos}

Apesar de existir um sistema de coleta dos resíduos sólidos domésticos pela Companhia Beneficiadora de Lixo - COBEL, ou por outras empresas contratadas pela Prefeitura Municipal de Maceió, é comum a acumulação local desses resíduos, formando verdadeiros lixões. 


\section{QUADRO 01 - Caracterização das Empresas do Distrito Industrial Governador Luiz}

Cavalcante

\begin{tabular}{|c|c|c|c|c|c|c|c|c|c|}
\hline \multirow{2}{*}{\multicolumn{2}{|c|}{ IDENTIFICAÇÃO }} & \multirow{3}{*}{$\begin{array}{l}\text { ATIVIDADE } \\
\text { Fabricação de } \\
\text { refrigerantes }\end{array}$} & \multirow{3}{*}{\begin{tabular}{|c|}
$\begin{array}{c}\mathrm{N}^{0} \text { de } \\
\text { Empre- } \\
\text { gados }\end{array}$ \\
440 \\
\end{tabular}} & \multicolumn{3}{|c|}{ EFLUENTES } & \multicolumn{3}{|c|}{ EFLUENTES LÍQUÍDOS } \\
\hline & & & & \multirow{2}{*}{\begin{tabular}{l}
\multicolumn{1}{c|}{ Sólidos } \\
coleta seletiva \\
queima do que \\
sobra
\end{tabular}} & \multirow{2}{*}{$\begin{array}{c}\text { Líquidos } \\
\text { Lavagem de } \\
\text { frascos e } \\
\text { equipamentos } \\
\left(500 \mathrm{~m}^{3} / \mathrm{dia}\right)\end{array}$} & \multirow{2}{*}{$\begin{array}{c}\text { Gasosos } \\
\text { Combustão } \\
\text { de óleo } \\
\text { B.P.F. } \\
\text { (Caldeira) }\end{array}$} & \multirow{2}{*}{$\begin{array}{l}\text { Tratamento } \\
\text { - } \\
\text { Desarenador } \\
\text {-Lagoa } \\
\text { anaeróbica } \\
\text {-Lagoa } \\
\text { facultativa }\end{array}$} & \multirow{2}{*}{\begin{tabular}{|c|}
$\begin{array}{c}\text { Disposição } \\
\text { Final }\end{array}$ \\
Lagoa 1 \\
Distrito \\
Industrial
\end{tabular}} & \multirow{2}{*}{\begin{tabular}{|r|} 
Moni \\
$T$ \\
$P$ \\
DBO \\
DC
\end{tabular}} \\
\hline 01 & $\begin{array}{c}\text { Companhia } \\
\text { Alagoana de } \\
\text { Refrigerantes } \\
\text { (Coca-Cola) }\end{array}$ & & & & & & & & \\
\hline 02 & $\begin{array}{l}\text { Introsuc - } \\
\text { Indústria } \\
\text { Tropical de } \\
\text { Sucos S.A. }\end{array}$ & $\begin{array}{l}\text { Fabricação de } \\
\text { sucos e } \\
\text { concentrados } \\
\text { de frutos }\end{array}$ & 36 & $\begin{array}{c}\text { Coletados por } \\
\text { terceiros para } \\
\text { ração animal } \\
\text { e } \\
\text { compostagem }\end{array}$ & $\begin{array}{l}\text { Lavagem de } \\
\text { frutas } \\
\left(20 \mathrm{~m}^{3} / \mathrm{h}\right)\end{array}$ & $\begin{array}{l}\text { Combustão } \\
\text { de óleo } \\
\text { B.P.F. } \\
\text { (Caldeira) }\end{array}$ & $\begin{array}{l}\text { Lagoas de } \\
\text { estabiliza- } \\
\text { ção } \\
\text { funcionando } \\
\text { como lagoas } \\
\text { de infiltração }\end{array}$ & $\begin{array}{c}\text { Infiltração } \\
\text { no solo }\end{array}$ & \\
\hline 03 & $\begin{array}{l}\text { AFC Com. e } \\
\text { Rep. Ltda. } \\
\text { (Adubo } \\
\text { Superfértil) }\end{array}$ & $\begin{array}{c}\text { Preparação de } \\
\text { adubos } \\
\text { fertilizantes }\end{array}$ & 40 & $\begin{array}{c}\text { Raspa } \\
\text { vendida para } \\
\text { agricultores }\end{array}$ & $\begin{array}{c}\text { Lavagem de } \\
\text { esteiras e } \\
\text { equipamentos }\end{array}$ & $\begin{array}{l}\text { Poeira } \\
\text { devido à } \\
\text { mistura } \\
\text { das } \\
\text { matérias- } \\
\text { primas } \\
\end{array}$ & $\begin{array}{c}\text { Drenagem } \\
\text { direta para a } \\
\text { Lagoa } 2 \text { do } \\
\text { Distr. Ind., } \\
\text { sem } \\
\text { tratamento } \\
\end{array}$ & $\begin{array}{l}\text { Lagoa } 2 \\
\text { Distrito } \\
\text { Industrial }\end{array}$ & \\
\hline 04 & $\begin{array}{l}\text { Ibratin } \\
\text { Nordeste } \\
\text { Ltda. }\end{array}$ & $\begin{array}{c}\text { Fabricação de } \\
\text { tintas }\end{array}$ & 37 & $\begin{array}{l}\text { Coletados por } \\
\text { terceiros }\end{array}$ & $\begin{array}{l}\text { Lavagem de } \\
\text { máquinas } \\
\left(01 \mathrm{~m}^{3} / \mathrm{h}\right)\end{array}$ & & $\begin{array}{l}\text { Coagulação } \\
\text { com sulfato } \\
\text { de alumínio, } \\
\text { seguido de } \\
\text { decantação }\end{array}$ & $\begin{array}{c}\text { Reutilização } \\
\text { do efluente } \\
\text { não- } \\
\text { decantado }\end{array}$ & \\
\hline 05 & $\begin{array}{c}\text { Kiola } \\
\text { Indústria e } \\
\text { Comércio } \\
\text { Ltda. }\end{array}$ & $\begin{array}{l}\text { Fabricação de } \\
\text { produtos domi- } \\
\text { sanitários }\end{array}$ & 10 & $\begin{array}{c}\text { Não } \\
\text { especificado } \\
\text { (queima) }\end{array}$ & $\begin{array}{l}\text { Limpeza da } \\
\text { fábrica } \\
\text { (resíduo de } \\
\text { detergente) }\end{array}$ & & & $\begin{array}{l}\text { Infiltração } \\
\text { no solo } \\
\text { através de } \\
2 \\
\text { sumidouros }\end{array}$ & \\
\hline 06 & $\begin{array}{l}\text { Supermix } \\
\text { Concreto } \\
\text { S.A. }\end{array}$ & Concretagem & 12 & $\begin{array}{l}\text { Papéis e } \\
\text { outros }\end{array}$ & $\begin{array}{l}\text { Lavagem do } \\
\text { carro } \\
\text { transportador } \\
\text { de concreto }\end{array}$ & & $\begin{array}{l}02 \text { caixas de } \\
\text { decantação }\end{array}$ & $\begin{array}{l}\text { Crenagem } \\
\text { natural do } \\
\text { terreno }\end{array}$ & \\
\hline 07 & $\begin{array}{l}\text { IFRIL - } \\
\text { Indústria de } \\
\text { Frios e } \\
\text { Pesca Ltda. }\end{array}$ & $\begin{array}{l}\text { Beneficiamento } \\
\text { de peixes e } \\
\text { crustáceos }\end{array}$ & 60 & $\begin{array}{c}\text { Não } \\
\text { especificados }\end{array}$ & $\begin{array}{l}\text { Água usada no } \\
\text { beneficiamento }\end{array}$ & & Lagoas & $\begin{array}{c}\text { Não há } \\
\text { informação }\end{array}$ & \\
\hline 08 & $\begin{array}{c}\text { LIFAL - } \\
\text { Laboratório } \\
\text { Farmacêutico } \\
\text { de Alagoas }\end{array}$ & $\begin{array}{l}\text { Fabricação de } \\
\text { produtos } \\
\text { farmacêuticos }\end{array}$ & 179 & $\begin{array}{c}\text { Vidros, } \\
\text { papelão, } \\
\text { plásticos, } \\
\text { pós, } \\
\text { (coletados } \\
\text { pela } \\
\text { Prefeitura) }\end{array}$ & $\begin{array}{l}\text { Esgotos } \\
\text { sanitários e } \\
\text { efluentes } \\
\text { industriais }\end{array}$ & & $\begin{array}{c}\text { Fossa / } \\
\text { sumidouros } \\
\text { Tanque de } \\
\text { coleta / } \\
\text { infiltração }\end{array}$ & $\begin{array}{l}\text { Infiltração } \\
\text { no solo }\end{array}$ & \\
\hline
\end{tabular}

Fonte: V \& S ENGENHEIROS CONSULTORES S/C (1998) 


\section{6 - Sistema de Drenagem}

A área de estudo está sujeita a grandes inundações por águas pluviais devido a sua topografia plana com ocorrência de depressões ou bacias endorreicas. Para evitar estas inundações foram construídas duas lagoas nas áreas mais baixas, sendo uma no Distrito Industrial Governador Luiz Cavalcante e outra no Conjunto Habitacional Salvador Lira.

Essas lagoas são clandestinamente utilizadas como corpos receptores para efluentes domésticos e industriais.

No atual projeto da macrodrenagem dessa região, estão previstas a ampliação das duas lagoas acima citadas e a construção de uma nova. As águas excedentes destas lagoas serão, segundo o projeto, drenadas para o rio Jacarecica.

\section{7 - Sistema de Saneamento}

A disposição local de esgotos dos conjuntos habitacionais é através de sistemas de fossas e sumidouros distribuídos espacialmente sem nenhum critério técnico, em relação às baterias de poços para captação de água subterrânea.

Estes sistemas de esgotamento sanitário podem ser individuais, isto é: por unidade habitacional, ou condominiais, quando atendem simultaneamente 100 a 500 casas.
Os sumidouros com 2 ou 3 metros de diâmetro e profundidade média de 40 metros, são dimensionados considerando uma taxa de absorção média de 50 litros $/ \mathrm{m}^{2} / \mathrm{dia}$.

Quando, devido a problemas construtivos, esses sistemas de esgotamento sanitários extravasam, o excedente é desviado para lagoas escavadas nas proximidades, sem os devidos cuidados técnicos, tais como impermeabilização.

O Campus A. C. Simões da Universidade Federal de Alagoas e o Hospital Universitário, situados no centro da área de estudo, têm sistema de esgotamento sanitário semelhante aos dos conjuntos habitacionais.

A fim de tratar principalmente os efluentes oriundos do Hospital Universitário, foi construído, posteriormente, um sistema formado por duas lagoas facultativas, cuja disposição dos efluentes é feita por maturação, evaporação e infiltração.

\section{ANÁLISE DAS POSSIBILIDADES DE CONTAMINAÇÃO}

Alguns poços para captação de água foram construídos sem nenhum critério técnico, principalmente em relação a proteção sanitária, facilitando a migração direta de poluentes da superfície até o aquífero. A maioria dos poços desativados 
existentes na área, não foram tamponados com cimento, ficando a água subterrânea também exposta à contaminação direta.

$\mathrm{Na}$ região dos tabuleiros costeiros é bastante utilizada a fertirrigação da canade-açúcar com solução aquosa de vinhoto, efluente do processo de produção nas usinas de açúcar e álcool, muito rico em potássio, ferro, cálcio e magnésio. CAVALCANTE et al. (1994) cita teores de $126 \mathrm{mg} / \mathrm{l} \mathrm{de} \mathrm{K} \mathrm{K}^{+}, 12,55 \mathrm{mg} / \mathrm{l} \mathrm{de} \mathrm{Fe}^{++}, 40 \mathrm{mg} / \mathrm{l}$ de $\mathrm{Ca}^{++}$(em mg/l de $\mathrm{CaCO}_{3}$ ) e $154 \mathrm{mg} / \mathrm{l} \mathrm{de}$ $\mathrm{Mg}^{++}$(em $\mathrm{mg} / \mathrm{l}$ de $\mathrm{CaCO}_{3}$ ) encontrados na água de um poço localizado nas proximidades, ao norte da área de estudo.

A contaminação de água subterrânea em área cultivada com cana-de-açúcar também foi constatada em Paripueira, a nordeste da área de estudo, conforme análises físico-químicas realizadas durante o período de 1983 a 1996, que apresentaram valores de $\mathrm{pH}$ decrescentes de 6,4 a 4,24 e valores crescentes de nitratos entre 0,20 e $8,25 \mathrm{mg} / \mathrm{l}$, (CAVALCANTE et al., 1996).

Das indústrias cadastradas, conforme Quadro 01, as de refrigerantes, adubos, tintas e produtos farmacêuticos, devido a qualidade de seus efluentes, representam maior potencial de risco à contaminação das águas subterrâneas.

Alguns sistemas isolados de tratamento e disposição final dos efluentes do Distrito Industrial Governador Luiz
Cavalcante, construídos fora das exigências técnicas e sem manutenção periódica, constituem, também, um risco de contaminação para os sistemas aqüíferos.

A evolução de sódio e potássio da água em dois poços do Distrito Industrial Governador Luiz Cavalcante, durante o período 1987/1993, comprova a degradação da água subterrânea causada provavelmente por efluente líquidos, (CAVALCANTE et al 1994).

Dos 13 postos de distribuição de derivados de petróleo cadastrados na área, quatro deles já operam há mais de 30 anos, podendo já ter vazamento de combustíveis e consequentemente contaminar as águas subterrâneas.

A acumulação de lixo tem causado, localmente, a degradação do solo com a alteração de suas características física, química e biológica, provocando a proliferação de vetores prejudiciais à saúde pública, podendo causar impacto nos aqüíferos que são os únicos mananciais economicamente disponíveis na região.

As lagoas para amortecimento de cheias do sistema de drenagem da região, são também utilizadas como corpos receptores de efluentes industriais $\mathrm{e}$ domiciliares, sendo, assim, um potencial risco para contaminação dos sistemas aqüíferos. 
Os sistemas de disposição local de esgotos descritos no capítulo anterior, poderão causar contaminação do aqüífero por microorganismos patogênicos e produtos de biodegradação de excretas humanas, como nitratos. Quando os poços para explotação de água subterrânea estão próximos aos sumidouros e não são construídos conforme as normas técnicas recomendadas, o risco de contaminação é maior.

WANDERLEY (1980), fez diversas recomendações para diminuir o risco de contaminação das águas subterrâneas causada por esses sistemas de esgotamento, destacando-se, entre elas, um rigoroso monitoramento com análises físico-químicas das águas dos poços que abastecem os conjuntos habitacionais.

\section{GRAU DE VULNERABILIDADE DAS ÁGUAS SUBTERRÂNEAS}

A avaliação preliminar do grau de vulnerabilidade natural em relação ao potencial de risco de contaminação dos aqüíferos foi feita utilizando a metodologia recomendada por FOSTER \& HIRATA (1991), que leva em consideração o tipo dos sistemas aqüíferos, a litologia da zona não saturada e a profundidade da água.

Assim, foram elaborados mapas indicando os diversos tipos de aqüíferos e profundidade de água. De acordo com esses mapas, os sistemas aquíferos são predominantemente confinados. Somente no extremo oeste e em uma faixa que se estende de sudoeste para noroeste os sistemas comportam-se como livres. A profundidade da água varia de 15 a 87 metros.

A litologia da zona não saturada é extensivamente representada por sedimentos não consolidados.

A partir dos mapas acima mencionados e da litologia dos diversos sistemas aqüíferos, foi composto o mapa de vulnerabilidade natural, apresentado na Figura 06.

Conforme este mapa, mais de $80 \%$ da área apresenta vulnerabilidade baixa, enquanto no restante, a vulnerabilidade é moderada. 


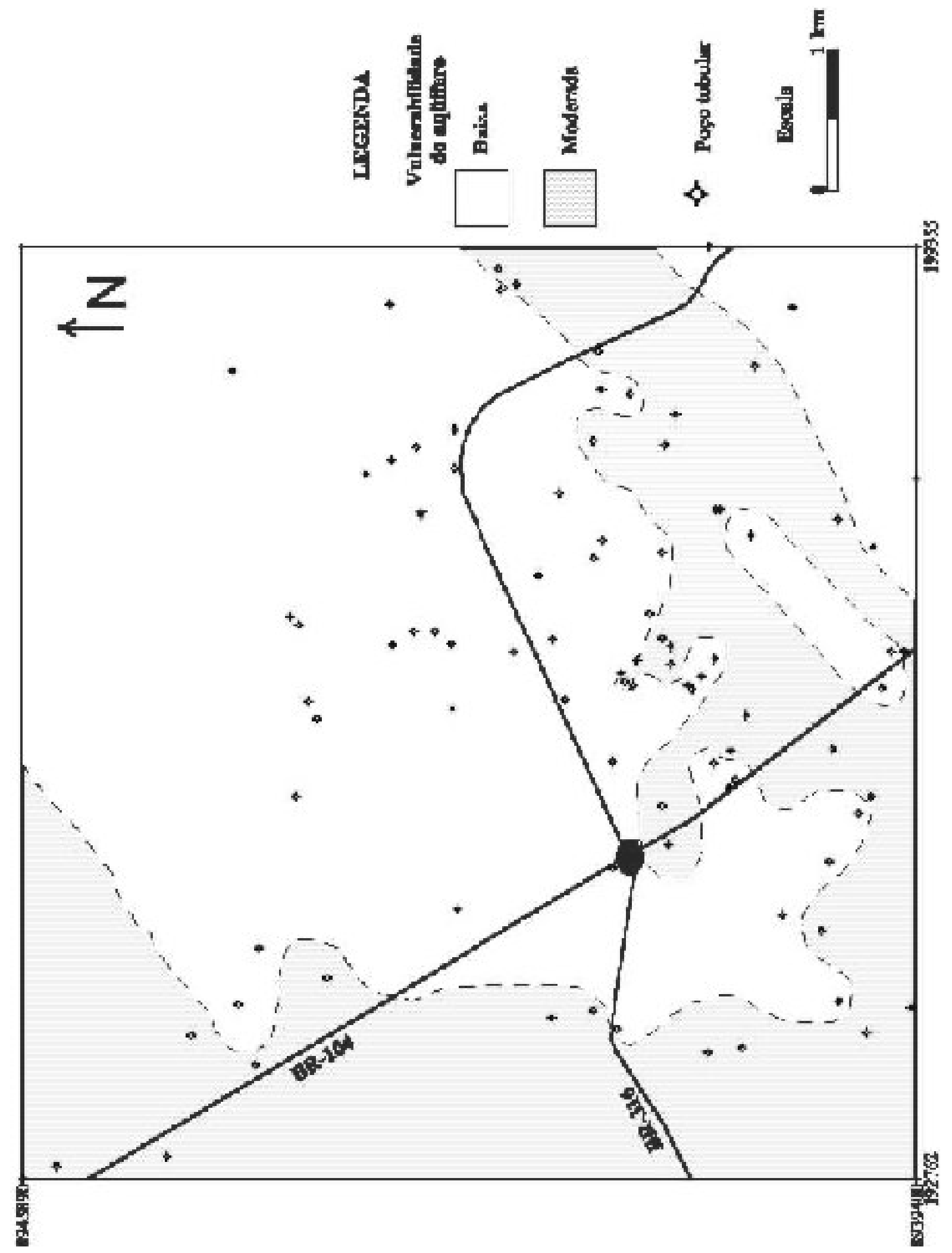

Figura 06 - Mapa de vulnerabilidade dos aqǘferos da área 


\section{CONCLUSÕES}

Apesar da existência de diversas atividades potencialmente poluidoras, descritas no item 6, o risco de contaminação dos sistemas aqüíferos é atenuado principalmente na parte onde a vulnerabilidade é baixa. No entanto, no domínio de vulnerabilidade moderada, poderá haver contaminação devido a de esgotos domiciliares. alguma atividade de grande potencial de risco, tais como: os sistemas de esgotamento sanitário, as indústrias que geram efluentes líquidos, os postos de combustíveis e, principalmente, as lagoas que constituem o sistema de drenagem, escavadas para atenuar as cheias da região, mas que também são utilizadas como receptoras de efluentes industriais e

\section{BIBLIOGRAFIA}

BRASIL - SUDENE - 1990. Dados hidrometeorológicos do Nordeste. Recife.

CAVALCANTE, A.T., WANDERLEY, P.R. de M. \& LIMA, R.C. de A. - 1992. As reservas dinâmicas dos sistemas aqüíferos Barreiras e Barreiras/Marituba a partir da análise das hidrógrafas dos rios Pratagy, Messias e Remédios. Maceió - Alagoas. Anais do $10^{\circ}$ Simpósio de Recursos Hídricos do Nordeste. Recife. Pernambuco, p. 397-402.

CAVALCANTE, A.T. - 1978. Recursos hídricos subterrâneos da área de Maceió Alagoas - Brasil. Dissertação de Mestrado apresentada à Universidade Federal de Pernambuco - Recife, p. 204.

CAVALCANTE, A.T. e WANDERLEY P.R. de M. - 1982. Recursos hídricos na área do Campus A. C. Simões - UFAL, Tabuleiro do Martins, Maceió - AL. Revista Scientia ad Sapientiam - UFAL, ano V, № 10, dezembro, Maceió - AL, p. 22-28.

CAVALCANTE, A.T., BARROSO, C.M.R., WANDERLEY, P.R. de M., SANTOS, R.C. de A.L. \& SANTOS, R.Q. - 1994. Impactos ambientais sobre os aquíferos da grande Maceió- Alagoas. Anais do $8^{\circ}$ Congresso Brasileiro de Águas Subterrâneas. Recife. Pernambuco. pp.190-199.

CAVALCANTE, A.T., SANTOS, R.C. de A.L. \& SANTOS, R.Q. - 1996. Recursos hídricos subterrâneos da região de Paripueira - Alagoas - Brasil. Anais do III Simpósio de Recursos Hídricos do Nordeste. Salvador . Bahia. - pp. 143-148.

FEIJÓ, Flávio J. - 1994. Bacias de Sergipe e Alagoas. Boletim de Geociências da PETROBRÁS, N 1, vol. 8, Rio de Janeiro. pag.149 - 161. 
FOSTER, S. S. D e HIRATA. R.D. - 1991. Determinación del riesgo da contaminación de águas subterrâneas. Una metodologia baseada em dados existentes. CEPIS. Lima. Peru. $81 \mathrm{p}$.

MABESSONE, J..M.; CASTRO, C. de - 1975. Desenvolvimento geomorfológico do Nordeste Brasileiro. Boletim do Núcleo do Nordeste da Sociedade Brasileira de Geologia. $N^{0}$ 3. Recife. Pernambuco. p. 5 -37.

SCHALLER, H., - 1969. Revisão estratigráfica da Bacia Sedimentar SergipelAlagoas. Boletim Técnico da PETROBRÁS. v. 12. N 1.Rio de Janeiro. pp. 21-85.

THORNTHWAITE, C.W.; MATHER, J.R. - 1955. The water balance. Publications in

Climatology. New Jersey: Drexel Institute of Technology, 104p.

TUCCI, C. E. M. (org.) - 1993. Hidrologia - Ciência e aplicação. Ed. da Universidade Federal do Rio Grande do Sul. ABRH - EDUSP. Porto Alegre. 943 p.

V \& S ENGENHEIROS CONSULTORES S/C - 1998. Macro drenagem do grande Tabuleiro do Martins. Estudo de impacto ambiental - EIA, Diagnóstico ambiental. Vol. 2. ADEDI - Associação das Empresas do Distrito Industrial Governador Luiz Cavalcante - Convênio SUDENE.

WANDERLEY, P. R. de M. - 1980. Contribuição geológica na prevenção da poluição do "Aqüífero Barreiras" - Tabuleiro do Martins - Maceió - Al. Scientia ad Sapientiam - ano III, Nº 5. - Maceió - Alagoas. pp. 36-40. 